\title{
De los acarreadores de oxígeno (HbCO) a los polimerosomas. Una mirada a las células artificiales
}

\author{
Norma Angélica Noguez-Méndez, ${ }^{* *}$ Carlos Tomás Quirino-Barreda,** \\ Susana Aurora Macín-Cabrera, ${ }^{* *}$ Virginia Eustolia Melo-Ruíz** y \\ Alejandro Rubio-Martínez***
}

\begin{abstract}
RESUMEN: Los sustitutos de sangre artificial poseen varias ventajas sobre las transfusiones donde participan donadores, por lo que se ha desarrollado sangre artificial tomando en consideración la función principal de la sangre, que es el transporte de oxígeno a los tejidos por medio de los eritrocitos. Se han sugerido dos estrategias para el desarrollo de acarreadores de oxígeno: el enfoque biomimético con Hemoglobin-based oxygen carriers ( $\mathrm{HBOC}$ por sus siglas en inglés) y el enfoque abiótico. El primer enfoque imita la naturaleza en la forma de transportar el oxígeno a los tejidos, mientras que el segundo utiliza productos químicos sintéticos para lograr el mismo resultado. Así, el origen de las células artificiales está relacionado con los acarreadores de oxígeno en la forma de polihemoglobinas y hemoglobinas conjugadas y aunque una célula completamente artificial equiparable al glóbulo rojo es todavía un sueño, el desarrollo de membranas lipídicas, poliméricas biodegradables y nanopartículas, son un paso hacia esa posibilidad.
\end{abstract}

PALABRAS CLAVE: células artificiales, acarreadores de oxígeno, HBCO, polimerosomas, membranas poliméricas.

ABSTRACT: Artificial blood substitutes have several advantages over blood transfusion from donors, making that oxygen transport to tissues of the blood via erythrocytes, the main challenge of artificial blood development. Two strategies have been suggested for the development of oxygen carriers: the biomimetic approach HBOCs (Hemoglobin-based oxygen carriers) and abiotic approach. The first approach mimics nature in the form of transport oxygen to the tissues, while the second uses synthetic chemicals to achieve the same result. Thus, the source of artificial cells is related to the carriers of oxygen in the form of polihemoglobins and conjugated hemoglobins and although a completely artificial cell comparable to the red blood cell is still a dream, the development of lipid membranes, biodegradable polymer and nanoparticles, are astep towards that possibility.

KEYWORDS: artificial cells, oxygen carriers, HBOC, polymersomes, polymeric membranes.

* Agradecimiento: Los autores agradecen el financiamiento recibido de la Secretaría de Ciencia, Tecnología e Innovación (SECITI), del gobierno del Distrito Federal, mediante el proyecto: Obtención y evaluación de nanomedicinas para resolver problemas de micosis mucocutáneas y prevención de fotodermatosis y cáncer en piel; convenio de colaboración UAM-SECITI No. ICYTDF/152/2012 e ICYTDF/152/2013 (Clave interna UAM: 912010).

** Laboratorio: Farmacia Molecular y Liberación Controlada, Unidad Interdisciplinaria de Docencia, Investigación y Servicio (UIDIS). Edificio “N”, Universidad Autónoma Metropolitana Unidad Xochimilco (UAM-X), Calzada del Hueso 1100, Col. Villa Quietud, Delegación Coyoacán,C.P. 04960 México, D F.

*** Laboratorio de Polímeros, Departamento de Química. Instituto Tecnológico de Querétaro. Correspondencia: (nanoguez@correo.xoc.uam.mx), (cquirino@correo.xoc.uam.mx), (macinsu@prodigy.net.mx), (vmelo@correo.xoc.uam.mx), (rumal65@yahoo.com.mx). 


\section{Introducción}

A pesar de las diferencias entre los antígenos eritrocitarios reflejadas en los sistemas de grupos sanguíneos, la sangre es el tejido humano que se comparte más fácilmente, tal es el caso de las transfusiones, que salvan miles de vidas anuales. Una transfusión es la transferencia de sangre entera o sus componentes (sólo eritrocitos o plasma) en el torrente sanguíneo. Si bien los componentes normales de las membranas plasmáticas eritrocitarias del donador pueden causar respuestas antígeno-anticuerpo nocivas en el receptor y aunado a ello se tiene como problemas su limitada disponibilidad y vida corta de almacenamiento (estimada en 15 días en refrigeración, la cual puede ser extendida a 42 días empleando agentes anticoagulantes), así como la posibilidad de transmisión de enfermedades infecciosas y posibles incompatibilidades, la demanda de este fluido en caso de cirugías de rutina y traumatológicas, desastres naturales, problemas sociales y guerras, lo hace un fluido biológico de alta importancia (Gaucher et al., 2006).

\section{¿Célula artificial y sangre artificial?}

La transfusión de sangre es una necesidad, especialmente en los casos de emergencia (tabla 1) en los que se presenta choque hipovolémico, consistente en la pérdida mayor a un $20 \%$ del volumen normal de sangre o en traumas penetrantes que conllevan a la pérdida aguda de sangre externa secundaria. El tratamiento médico inicial para el choque hipovolémico tiene como finalidad el arreglo de tres áreas principales: maximizar el suministro de oxígeno, restaurar el flujo sanguíneo y la restitución de líquidos. Sin embargo, la escasa disponibilidad o la no existencia de volúmenes suficientes de sangre para atender la demanda de este fluido fisiológico ha llevado a países como Estados Unidos de Norteamérica, Japón y China o a regiones del mundo como Europa,

TABLA 1. Unidades de sangre requeridas por paciente en diferentes situaciones.

\begin{tabular}{|l|l|}
\hline $\begin{array}{l}\text { SITUACIONES QUE INVOLUCRAN } \\
\text { EL EMPLEO DE SANGRE }\end{array}$ & UNIDADES REQUERIDAS POR PACIENTE \\
\hline Accidente automovilístico & 50 unidades de sangre \\
\hline Cirugía de corazón & 6 unidades de sangre \\
& 6 unidades de plaquetas \\
\hline & 40 unidades de sangre \\
Trasplante de órganos & 30 unidades de plaquetas \\
\hline \multirow{2}{*}{ Trasplante de médula ósea } & 25 unidades de plasma fresco congelado \\
\hline
\end{tabular}

Fuente: <http://www.google.com/patents/EP2560625A2>, 14/01/2014; 21:37. 
FIGURA 1. Clasificación de los sustitutos sanguíneos de acuerdo con el desarrollo tecnológico.

$$
\text { Sustituto sanguíneos }\left\{\begin{array}{l}
\text { Acarreadores de oxígeno } \\
\text { Oxígeno terapéutico } \\
\text { Sustitutos de glóbulo rojo }
\end{array}\right.
$$

a obtener "sustitutos de sangre u oxígeno terapéutico" con distinto nivel de desarrollo tecnológico (figuras 1 y 2). Así, existen terapias alternativas que pueden sustituir la transfusión en casos clínicos en los que la sangre no está disponible en el banco de sangre o ésta es insuficiente (Gaucher, et al., 2006). No obstante lo anterior, aunque el desarrollo de esos tres tipos de sustitutos de sangre ha sido un activo campo de interés durante dos o tres decenios, estos sistemas no son todavía adecuados para reemplazar la sangre debido, entre otros factores, a su limitado tiempo de retención en la circulación, a la producción de un efecto vasoconstrictor no deseado y a la incertidumbre sobre la efectividad del transporte de oxígeno.

Los sustitutos de sangre artificial poseen varias ventajas sobre las transfusiones donde participan donadores, entre ellas están: a) la sangre artificial puede ser diseñada sin poseer ningún grupo antigénico en su superficie, b) puede garantizarse su esterilidad, eliminando la posibilidad de la transmisión de una infección y evitando las pruebas cruzadas de los grupos sanguíneos, y, c) facilidad de almacenamiento prolongado.

FIGURA 2. Dos prototipos de células artificiales: un acarreador de oxígeno (HBOC) y el perfluorocarbono (PFC), ambos son más pequeños que el glóbulo rojo (GR).

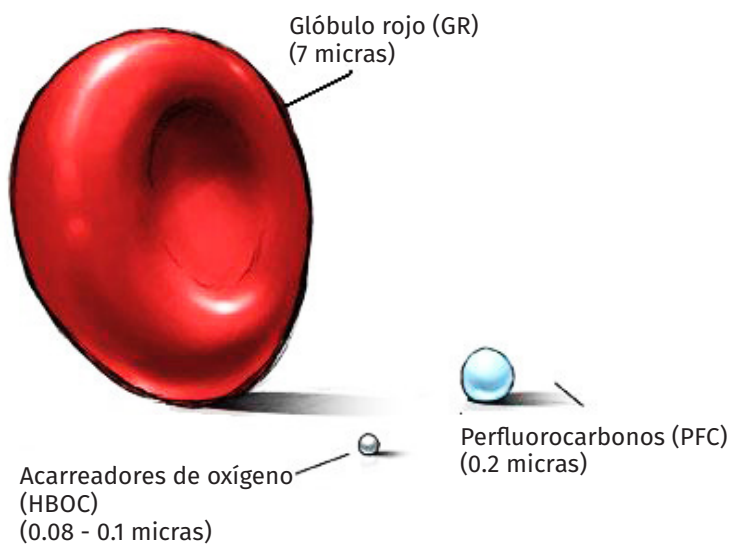

Fuente: Esquema adaptado de: <http://science.howstuffworks.com/innovation/everyday-innovations/artificial-blood4.htm>, 14/01/2014; 22:33. 
FIGURA 3. Sustitutos de células rojas.

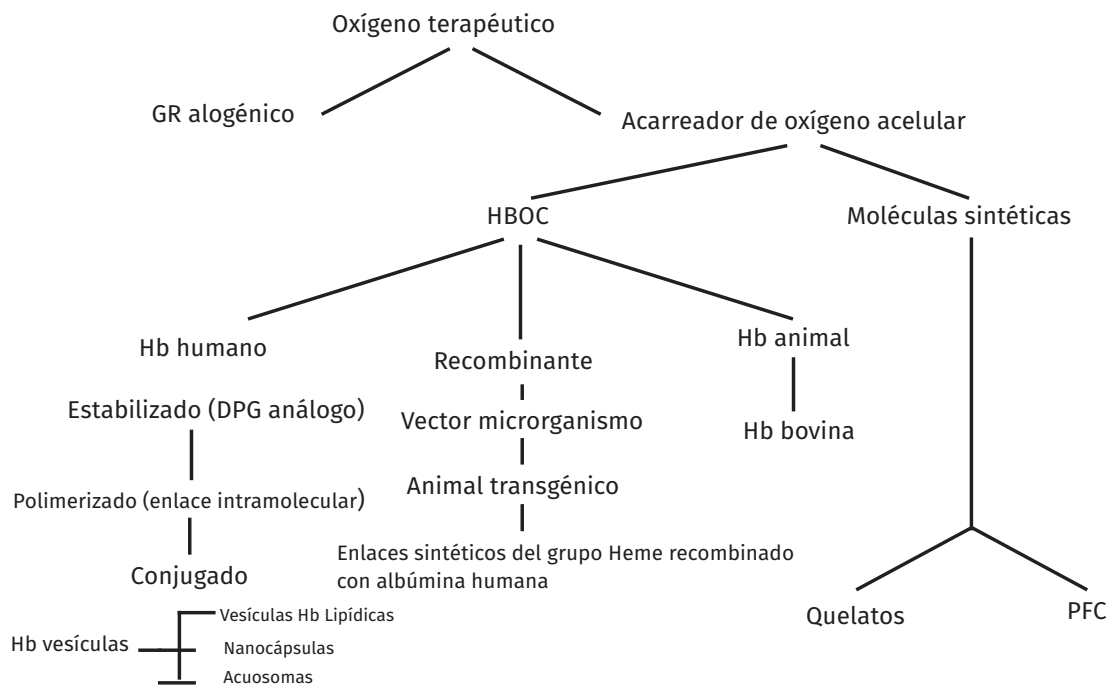

Fuente: Imagen tomada de Ness, P.M., Cushing M.M. (2007). Oxygen therapeutics. Archives of Pathology e Laboratory Medicine, 131: 734-41.

Para el desarrollo de sangre artificial se toma en consideración la función principal de la sangre: la transportación de oxígeno a los tejidos por medio del eritrocito (Chang, 2009). Se han sugerido dos estrategias para el desarrollo de acarreadores de oxígeno, es decir, el enfoque biomimético y el enfoque abiótico. El primer enfoque imita la naturaleza en la forma de transportar el oxígeno a los tejidos, mientras que el segundo enfoque utiliza productos químicos sintéticos para lograr el mismo resultado (figura 3) (Kjellstrom, 2003; Smith, et al., 2004; Ness y Cushing, 2007).

Los efectos colaterales de las soluciones de hemoglobina ( $\mathrm{Hb})$ son: vasoactividad, nefrotoxicidad, interferencia con el sistema fagocitario mononuclear, oxidación durante su almacenamiento, antigenicidad, pobre acarreo de oxígeno, liberación de histamina y depósitos de hierro. Debido a esto, no es posible administrar a la hemoglobina en su forma nativa, de ahí que sea necesario modificarla (tabla 2). El origen de las células artificiales está rela-

TABLA 2. Soluciones de hemoglobina modificada.

\begin{tabular}{|l|}
\hline 1. Hemoglobina bovina polimerizada \\
\hline 2. Hemoglobina humana recombinante \\
\hline 3. Hemoglobina transgénica \\
\hline 4. Hemoglobina microencapsulada \\
\hline 5. Soluciones perfluoroquímicas \\
\hline
\end{tabular}


TABLA 3. Células artificiales.

\begin{tabular}{|l|l|l|l|}
\hline $\begin{array}{l}\text { Acarreadores de } \\
\text { oxígeno artificial } \\
\text { (PEGylation) }\end{array}$ & $\begin{array}{l}\text { Ness, P.M. et al. } \\
2007\end{array}$ & $\begin{array}{l}\text { Conjugados de } \\
\text { albúmina-Heme }\end{array}$ & $\begin{array}{l}\text { Eastman, A. y } \\
\text { Minel JP, 2009 }\end{array}$ \\
\hline Hemoglobina/Heme & $\begin{array}{l}\text { Cheng, D.C. et al., } \\
2004\end{array}$ & $\begin{array}{l}\text { Hb transgénico/ } \\
\text { recombinante }\end{array}$ & $\begin{array}{l}\text { Dieryck, W. et al., } \\
1997\end{array}$ \\
\hline $\begin{array}{l}\text { Hb polimerizado } \\
\text { (glutaraldehído) }\end{array}$ & $\begin{array}{l}\text { Kaneda, S. et al., } \\
2009\end{array}$ & $\begin{array}{l}\text { Hbs anélidos (lombriz } \\
\text { de tierra) }\end{array}$ & $\begin{array}{l}\text { Hao Zhu et al., } \\
1996\end{array}$ \\
\hline Hb conjugada (PEG) & Winslow R.M., 2003 & Perfluorocarbonos (PFC) & Lowe, K.C., 2002 \\
\hline Vesículas de Hb & $\begin{array}{l}\text { Sakai, H. et al., } \\
2006\end{array}$ & $\begin{array}{l}\text { Polimerosomas } \\
\text { Dendrímeros }\end{array}$ & $\begin{array}{l}\text { Tanner, P. et al., } \\
2011 \text { y Ruth D. et } \\
\text { al., 2005 }\end{array}$ \\
\hline $\begin{array}{l}\text { HBOCS (Ácido poli } \\
\text { láctico-catalasa) }\end{array}$ & $\begin{array}{l}\text { D'Agnillo, F. y } \\
\text { Chang, T.M.S., 1998 }\end{array}$ & & \\
\hline
\end{tabular}

Fuente: La tabla fue desarrollada con base en la consulta que se hizo de los artículos. Es propia de los autores.

cionado con los acarreadores de oxígeno en la forma de polihemoglobinas y hemoglobinas conjugadas (Radillo-González y cols. 2004).

Aunque una célula completamente artificial equiparable al glóbulo rojo (GR) es todavía un sueño, el desarrollo de membranas lipídicas, poliméricas biodegradables y nanopartículas, son un paso hacia esa posibilidad. Se observa que los sustitutos sanguíneos consisten en entidades cada vez más complicadas, por ejemplo, acarreadores de oxígeno, acarreadores de oxígeno con antioxidantes y sustitutos de glóbulos rojos (tabla 3), (Schumacher y Ashenden, 2004; Napolitano, 2009; Eastman y Minei, 2009; Alayash, 2004; Lowe et al., 2003).

La primera célula artificial fue diseñada en 1957 en forma de célula roja y el uso clínico de células artificiales ha sido variado: como adsorbente para hemoperfusión, en forma rutinaria en procesos de intoxicación accidental o suicidas, cuando la diálisis no está disponible (tabla 4). Otras áreas de aplicación son en las que las células contienen enzimas para tratamientos enzimáticos, islotes para el tratamiento de la diabetes, hepatocitos para la insuficiencia hepática, sistemas de suministro de medicamentos y hormonas (Chang, 2006). En las últimas décadas el interés por la biotecnología, la biología molecular, la nanotecnología y la medicina regeneradora ha estimulado aún más el desarrollo de células artificiales en otros ámbitos, (Discher y Ahmed 2006; Meng et al., 2005; Teramura et al., 2003; Arifin y Palmer, 2003; Arifin, 2005).

Los tamaños de las células artificiales ahora oscilan entre las macrodimensiones, microdimensiones, dimensiones nanométricas y las dimensiones moleculares (figura 4), (Chang, 2005).

Las que están en dimensiones macro son adecuadas para la bioencapsulación de células, microrganismos y biorreactantes; aquellas en dimensiones 
Mundo Nano | Artículos | Vol. 7, No. 12, enero-junio, 2014 | www.mundonano.unam.mx

TABLA 4. Productos desarrollados a base de hemoglobina $(\mathrm{Hb})$ y fase de investigación clínica en que se encuentran a diciembre de 2013.

\begin{tabular}{|l|c|c|c|}
\hline \multicolumn{1}{|c|}{ PRODUCTO } & DERIVADO & $\begin{array}{c}\text { FASE DE } \\
\text { INVESTIGACIÓN }\end{array}$ & INDICACIÓN \\
\hline $\begin{array}{l}\text { Polyheme } \\
\text { (Northfield Labs) }\end{array}$ & Hb humana & III & Trauma/cirugía \\
\hline Hemopure (Biopure) & Hb bovina & III & Cirugía/hemodilución \\
\hline Hemolink (Hemosol) & Hb humana & III & Cirugía/hemodilución \\
\hline Sangart & Hb humana pegilada & I & Cirugía/hemodilución \\
\hline HemAssist (Baxter) & Hb humana & Terminado & Shock hemorrágico \\
\hline Optro (Somatogen) & Hb recombinante & Terminado & Cirugía/hemodilución \\
\hline Oxygent (Alliance) & Perfluobron & III & Cirugía/hemodilución \\
\hline
\end{tabular}

Fuente: <http://www.cancernetwoork.com./rewiew-article/blood-substitutes-how-close-solution/ page $/ 0 / 2>, 15 / 01 / 2014,12: 45 \mathrm{pm}$.

de micra son adecuadas para la encapsulación de enzimas, péptidos, vacunas, fármacos y otros materiales. Las células artificiales que están en las nanodimensiones se han empleado para sustitutos de sangre y vehículos para enzimas, péptidos y fármacos, entre otras aplicaciones. Las células de dimensiones moleculares se utilizan como sustitutos de sangre y enzimas reticuladas (Ming, 2004; Sharma et al., 2011; Napolitano, 2009). La modificación química de la hemoglobina (figura 5), mantiene la estabilidad en el torrente sanguíneo y también permite la entrega de oxígeno a los tejidos. Hasta la fecha hay cuatro fuentes potenciales de hemoglobina (tabla 5).

FIGURA 4. Células artificiales en otros ámbitos.

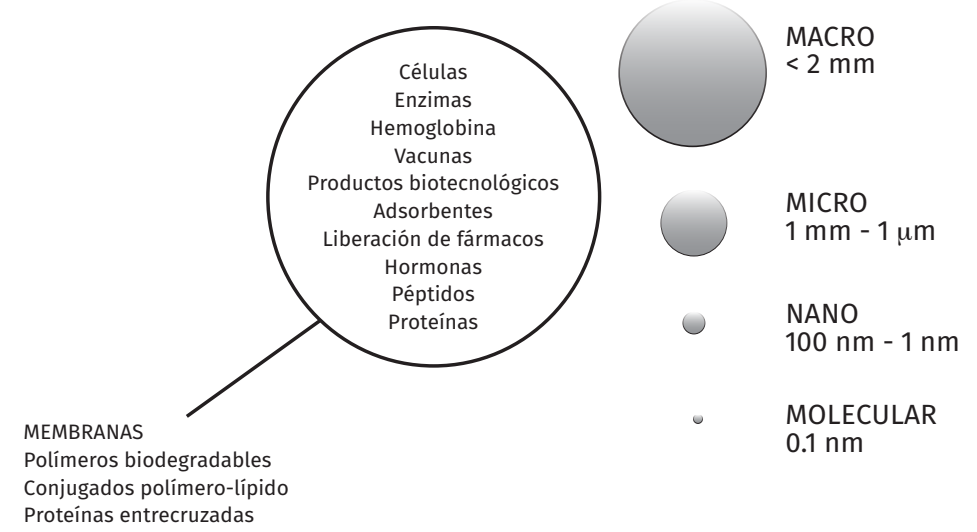

Fuente: Imagen tomada de Chang, T.M.S. (2005). Therapeutic applications of polymeric artificial cells. Nature Rewiews/Drug Discovery. March Vol. 4 (221-235). 
FIGURA 5. Modificación química de la hemoglobina.

Tetrámero entrecruzado

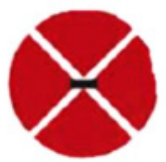

Polímero

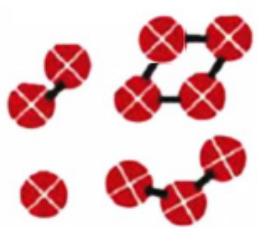

Tetrámero conjugado

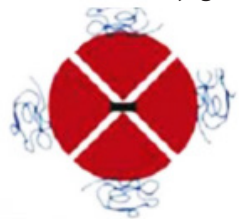

Vesícula lipídica

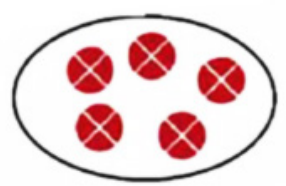

Fuente: Imagen tomada de Napolitano L.M. (2009) Hemoglobin-based oxygen carriers: First, second or third generation? Human or bovine? Where are we now? Critical Care Clinics, 25: 279-301.

TABLA 5. Fuentes potenciales de hemoglobina.

\begin{tabular}{|l|l|l|l|}
\hline \multicolumn{1}{|c|}{ ORIGEN } & \multicolumn{1}{|c|}{ EXPLICACIÓN } & \multicolumn{1}{c|}{ VENTAJAS } & \multicolumn{1}{c|}{ DESVENTAJAS } \\
\hline $\begin{array}{l}\text { Sangre } \\
\text { humana }\end{array}$ & Implica la extracción. & Recurso barato. & $\begin{array}{l}\text { No hay suficiente } \\
\text { número de } \\
\text { donadores. }\end{array}$ \\
\hline Sangre de vaca & $\begin{array}{l}\text { Utiliza Hb de la sangre } \\
\text { de vaca. }\end{array}$ & $\begin{array}{l}\text { Recurso barato, } \\
\text { reducción de las } \\
\text { modificaciones } \\
\text { químicas Hb. }\end{array}$ & $\begin{array}{l}\text { Efecto a largo plazo } \\
\text { desconocido en el } \\
\text { sistema inmune } \\
\text { humano. }\end{array}$ \\
\hline Microrganismo & $\begin{array}{l}\text { Producción a partir de } \\
\text { bacterias, hongos y } \\
\text { plantas genéticamente } \\
\text { modificadas. }\end{array}$ & $\begin{array}{l}\text { Una fuente de Hb puro, } \\
\text { libre de virus y otro } \\
\text { componente de sangre. }\end{array}$ & $\begin{array}{l}\text { Altos costos de } \\
\text { producción a gran } \\
\text { escala. }\end{array}$ \\
\hline $\begin{array}{l}\text { Animales } \\
\text { transgénicos }\end{array}$ & $\begin{array}{l}\text { Animales capaces de } \\
\text { producir Hb cuando } \\
\text { maduran. }\end{array}$ & Grandes volúmenes. & $\begin{array}{l}\text { Posibles objeciones } \\
\text { éticas al uso de } \\
\text { animales. }\end{array}$ \\
\hline
\end{tabular}

Fuente: Ming, 2004; Sharma, et al. 2011.

\section{Perfluorocarbonos (PFCS)}

Los PFCS son "aceites" sintéticos hechos solamente por átomos de carbono y flúor. Han sido desarrollados como materiales aislantes inactivos, en el Proyecto Manhattan durante la segunda guerra mundial. Los PFCs son estables y no reaccionan con tejidos vivos, pero poseen una gran capacidad para acarrear gases incluyendo el oxígeno, el dióxido de carbono y el nitrógeno. La temperatura de ebullición de los diversos PFCs difiere entre unos y otros. 
Pueden ser líquidos a temperatura ambiente y ser gaseosos a temperatura del cuerpo (<http://espanol.alertdiver.com/Perfluorocarbonos\#sthash.tmStmwOs.dpuf $>, 15 / 01 / 2014,12: 48$ pm).

Los perfluorocarbonos son líquidos sintéticos que disuelven grandes volúmenes de oxígeno y también tienen la capacidad de transporte de dióxido de carbono $\left(\mathrm{CO}_{2}\right)$.

Estos químicos líquidos primero se hicieron famosos en los años 70, cuando los científicos dirigidos por los profesores Lelan C. Clark y Frank Gollan (1966) mostraron que un ratón podía sobrevivir por hasta 10 minutos (figura 6).

Muchos científicos pensaron que el PFC líquido es la respuesta al desarrollo de un sustituto de sangre eficaz. Esta creencia es compatible con un número de las características favorables asociados al perfluorocarbono (tabla 6).

\section{Polimerosomas}

De las células artificiales mencionadas, las vesículas poliméricas (polimerosomas) son las que en años recientes han tenido una mayor atención, después del primer informe hecho en 1990 por Eisenberg, Bates y Discher (Goliath, 2005). Desde entonces, los bloques de copolímero anfipáticos, dendrímeros y derivados de fulerenos han sido clasificados como formadores de vesículas (Förster y Borchert, 2005) y, a su vez, representan una opción como vehículos de liberación de fármacos (Pata y Dan, 2003).

El empleo de bloques de copolímero para la generación de vesículas poliméricas es una nueva estrategia para el desarrollo de la encapsulación. Dependiendo de la longitud y la naturaleza química del copolímero, el polimerosoma resultante puede ser más robusto que el liposoma comparable a su

FIGURA 6. Ratón sumergido en una solución de PFC.

Fuente: Imagen tomada de: <http:/ / www.taringa.net/ posts/ciencia-educacion/12990955/Liquidos-respirables-Perfluorocarbono-oxigenado.html>, 15/01/2014, 12:38 pm.

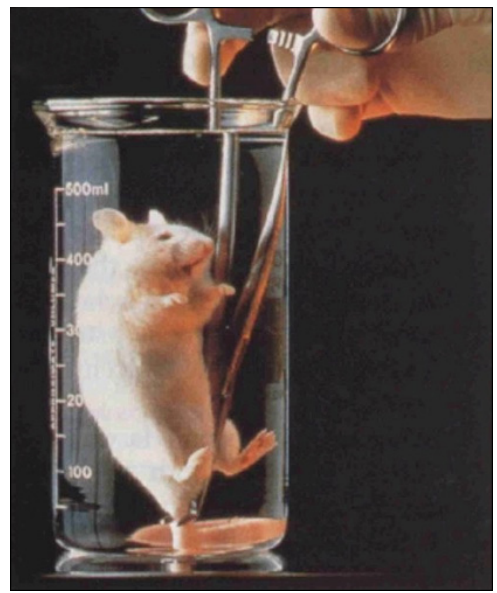


TABLA 6. Ventajas y desventajas de los perfluorocarbonos.

\begin{tabular}{|c|c|c|}
\hline $\begin{array}{l}\text { CARACTERISTIICAS DEL } \\
\text { PERFLUOROCARBONO }\end{array}$ & VENTAJAS & DESVENTAJAS \\
\hline $\begin{array}{l}\text { Alta solubilidad del } \\
\text { oxígeno. }\end{array}$ & $\begin{array}{l}\text { PFC disuelve altos volúmenes } \\
\text { de } \mathrm{O}_{2} \text { y } \mathrm{CO}_{2} \text {. } \\
\text { Se extraen fácilmente por los } \\
\text { tejidos del cuerpo. }\end{array}$ & $\begin{array}{l}\text { Antes de la administración, } \\
\text { PFC, éstos deben estar } \\
\text { preparados como emulsiones, } \\
\text { el perfluorocarbono no se } \\
\text { mezcla con plasma sanguíneo. }\end{array}$ \\
\hline $\begin{array}{l}\text { Síntesis de recurso no } \\
\text { biológico. }\end{array}$ & $\begin{array}{l}\text { No es transmisor de } \\
\text { enfermedades. }\end{array}$ & $\begin{array}{l}\text { Para disolver las cantidades } \\
\text { adecuadas de oxígeno en PFC, } \\
\text { se requiere que a los pacientes } \\
\text { se les administre del } 70-100 \% \\
\text { de oxígeno a través de una } \\
\text { máscara de respirar durante la } \\
\text { cirugía. }\end{array}$ \\
\hline Altamente estable. & $\begin{array}{l}\text { Altamente estable durante el } \\
\text { almacenamiento. } \\
\text { PFC no requiere la } \\
\text { modificación química, } \\
\text { porque no muestra desglose } \\
\text { metabólico en el cuerpo. }\end{array}$ & $\begin{array}{l}\text { En los ensayos clínicos en } \\
\text { humanos se ha observado el } \\
\text { desarrollo de síntomas gripales } \\
\text { en algunos pacientes. }\end{array}$ \\
\hline Químicamente inerte. & $\begin{array}{l}\text { PFC no sufre reacción } \\
\text { bioquímica en el cuerpo y } \\
\text { puede eliminarse del cuerpo } \\
\text { a través de los pulmones en } \\
\text { exhalación. }\end{array}$ & \\
\hline Fácil de esterilizar. & $\begin{array}{l}\text { Estructura estable, puede } \\
\text { soportar altas temperaturas, } \\
\text { lo cual permite la } \\
\text { esterilización. }\end{array}$ & \\
\hline Bajo costo. & $\begin{array}{l}\text { PFC puede ser producido en } \\
\text { calidad de grado médico en } \\
\text { una escala grande, comercial. }\end{array}$ & \\
\hline
\end{tabular}

Fuente: Cabrales, P. (2006).

tamaño (figura 7). El grosor de la membrana se controla por la variación en el grado de polimerización de los bloques de las moléculas individuales mientras que la fluidez y la permeabilidad de la membrana puede ser ajustada por el cambio de la temperatura de transición vítrea ( $\mathrm{Tg}$ ) del bloque hidrofóbico (Lorenceau et al., 2005).

El polimerosoma puede ser formado a partir de bloques de un copolímero usando disolventes orgánicos, acuosos o una mezcla de ambos (Discher et al., 2001). La formación se lleva a cabo en dos pasos, el primero consiste de una bicapa anfipática y el segundo la formación de la vesícula (figura 8) (Förster y Borchert, 2005).

Los polimerosomas pueden poseer diversas formas, como se muestra en 
FIGURA 7. Estructura típica de una vesícula lipídica y una vesícula polimérica.

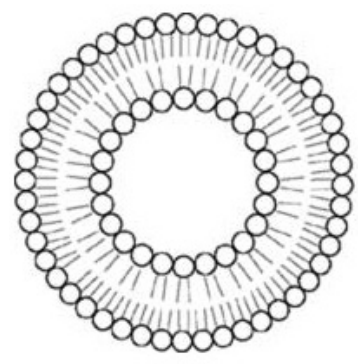

Liposoma

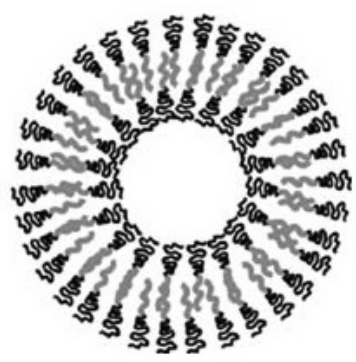

Polímero

Fuente: Imagen tomada de Förster, S. y Borchert, K. (2005). Encyclopedia of Polymer Science and Technology. John Wiley \& Sons.

la figura 9. Esto va depender de las condiciones del proceso de preparación: composición del copolímero, la naturaleza del disolvente y la temperatura del sistema (Soo y Eisenberg, 2004)

En la tabla 7 se muestra en línea de tiempo la evolución en el desarrollo de las células artificiales y sus aplicaciones. Los datos desde 1957 a 2006, corresponden a lo publicado por Chang (2007) y del 2007 al 2012, pertenecen a la investigación que realizaron los autores del presente artículo para conocer el estado del arte hasta nuestros días.

En el ámbito de la tecnología, el desarrollo de sustitutos sanguíneos en el mundo científico sigue avanzando en la búsqueda de una alternativa eficaz para los procedimientos de transfusión (generación de glóbulos rojos artificiales), y para tratamiento de enfermedades antineoplásicas con la finalidad de buscar la mejora en la calidad de vida de la población.

FIGURA 8. Esquema estructural de una bicapa anfipática de copolímero y la formación de la vesícula.

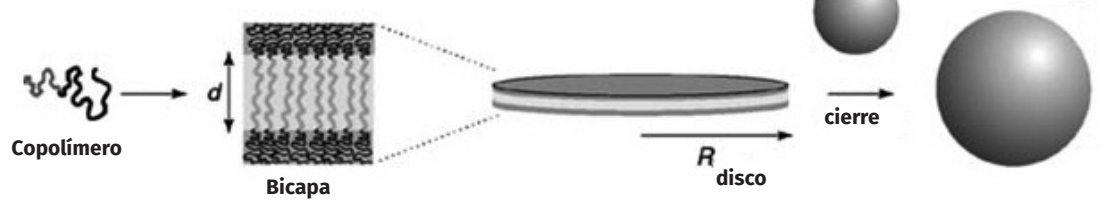

Fuente: Imagen tomada de Förster, S. y Borchert, K. (2005) Encyclopedia of Polymer Science and Technology. John Wiley \& Sons. 
FIGURA 9. Micrografias de diferentes tipos de vesículas: a) vesículas pequeñas y uniformes; b) vesículas grandes y polidispersas; c) vesículas atrapadas; d) vesículas de vacío concéntrico; e) cebollas, y, f) vesículas con tubos en la pared.
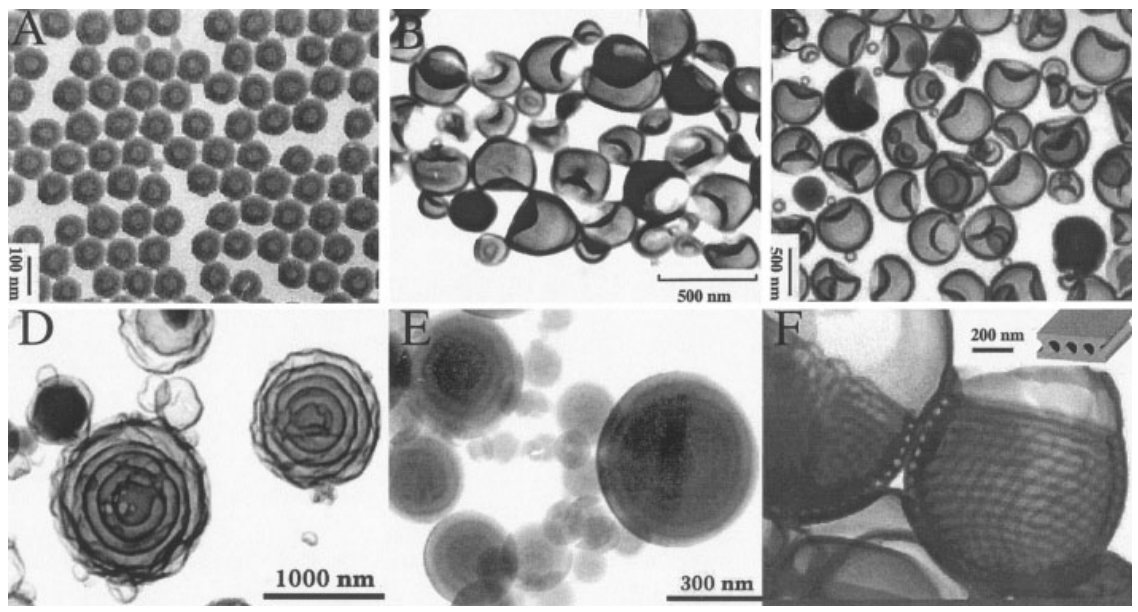

Fuente: Imagen tomada de Soo, P.L. y Eisenberg, A. Preparation of block copolymer vesicle in solution. Journal of Polymer Science: Part B: Polymer Physics. 42: 923-938, 2004.

TABLA 7. Conceptos y aplicaciones de las células artificiales poliméricas.

\begin{tabular}{|l|l|}
\hline AÑO & DESARROLLO \\
\hline 1957 Chang & $\begin{array}{l}\text { Primera célula artificial polimérica conteniendo hemoglobina y } \\
\text { enzimas (método de extrusión). }\end{array}$ \\
\hline $\begin{array}{l}\text { 1964 Chang } \\
\text { (Science) }\end{array}$ & $\begin{array}{l}\text { Célula artificial polimérica conteniendo enzimas y hemoglobinas } \\
\text { (coacervación interfacial, polimero conjugado con proteína). }\end{array}$ \\
\hline $\begin{array}{l}\text { 1964, 1965 Chang } \\
\text { 1964, 1965 Chang } \\
\text { 1966: Chang et al. }\end{array}$ & $\begin{array}{l}\text { Nanobiotecnología; entrecruzamiento de proteína (PolyHb) y } \\
\text { conjugado de Hb. } \\
\text { Método de extrusión por gota para encapsular células intactas } \\
\text { para terapia celular. }\end{array}$ \\
\hline 1965 Bangham et al. & $\begin{array}{l}\text { Microesferas de cristal líquido (liposoma) como modelo de } \\
\text { membrana. }\end{array}$ \\
\hline $\begin{array}{l}\text { 1965, 1972 a } \\
1973 b \text { Chang }\end{array}$ & $\begin{array}{l}\text { Tamiz molecular por cromatografía para la separación de células } \\
\text { artificiales. }\end{array}$ \\
\hline $\begin{array}{l}\text { 1965 Chang } \\
\text { 1966 Chang et al. } \\
1966 \text { Chang }\end{array}$ & $\begin{array}{l}\text { Células artificiales con multicomponentes intracelulares. } \\
\text { Microesferas con proteína. }\end{array}$ \\
\hline 1966 Chang & $\begin{array}{l}\text { Células artificiales con materiales magnéticos y material } \\
\text { biológico. }\end{array}$ \\
\hline 1966, 1969a Chang & $\begin{array}{l}\text { Célula artificial con membrana ultrafina conteniendo adsorbente } \\
\text { para hemoperfusión. }\end{array}$ \\
\hline 1966 Clark y Gollan & Fluorocarbono como acarreador de oxígeno. \\
\hline
\end{tabular}


Mundo Nano | Artículos | Vol. 7, No. 12, enero-junio, 2014 | www.mundonano.unam.mx

TABLA 7. Conceptos y aplicaciones de las células artificiales poliméricas.

\begin{tabular}{|c|c|}
\hline AÑo & DESARROLLO \\
\hline 1967 Chang et al. & $\begin{array}{l}\text { Célula artificial con membrana de complejo polisacárido para } \\
\text { biocompatibilidad. }\end{array}$ \\
\hline $\begin{array}{l}1968 \text { Chang y } \\
\text { Poznansky (Nature) }\end{array}$ & $\begin{array}{l}\text { Implante enzimático que contiene células artificiales para el } \\
\text { empleo en terapia enzimática. (Deficiencia congénita de catalasa } \\
\text { en ratones acatalacémicos). }\end{array}$ \\
\hline 1968 Bunn y Jandl & Entrecruzamiento de moléculas de hemoglobina. \\
\hline 1968 Geyer et al. & Efectividad del fluorocarbono en transfusión estudio animal. \\
\hline $\begin{array}{l}\text { 1969d Chang } \\
\text { 1972a Chang }\end{array}$ & $\begin{array}{l}\text { Célula artificial con membrana lípido-polímero o lípido } \\
\text { entrecruzado con polímero con un transportador cíclico. }\end{array}$ \\
\hline $\begin{array}{l}1970 \text { - } 1975 \text { Chang } \\
\text { et. al. }\end{array}$ & $\begin{array}{l}\text { Primer uso clínico de células artificiales en pacientes para } \\
\text { hemoperfusión. }\end{array}$ \\
\hline $\begin{array}{l}1971 \text { a Chang } \\
\text { (Nature) }\end{array}$ & $\begin{array}{l}\text { Célula artificial con implante enzimático para el tratamiento de } \\
\text { linfosarcoma en ratón. } \\
\text { Reticulado de hemoglobina con glutaraldehído } \\
\text { (polihemoglobina). }\end{array}$ \\
\hline 1971b Chang & $\begin{array}{l}\text { Nanobiotecnología: entrecruzamiento de hemoglobina con } \\
\text { glutaraldehído en PolyHb. Sustituto sanguíneo en pacientes. }\end{array}$ \\
\hline 1972a Chang & Primera monografía de célula artificial. \\
\hline $\begin{array}{l}\text { 1972b Chang } \\
\text { (Lancet) }\end{array}$ & $\begin{array}{l}\text { Hemoperfusión de células artificiales en paciente con grado IV } \\
\text { de coma hepático, recobra la conciencia. }\end{array}$ \\
\hline 1973 Gregoriadis & $\begin{array}{l}\text { Primer uso de liposomas para encapsular enzimas y fármacos. } \\
\text { Empleo de liberación controlada. }\end{array}$ \\
\hline 1975h Chang & Discusión del empleo de células artificiales en vacunas. \\
\hline $\begin{array}{l}1976 \text { Tam, } \\
\text { Blumenstein y Wong }\end{array}$ & Solución de Dextran con hemoglobina conjugada. \\
\hline 1976 Bonhard et al. & $\begin{array}{l}\text { Desarrollo de glutaraldehído entrecruzado Poly Hb y su empleo } \\
\text { como sustituto sanguíneo. }\end{array}$ \\
\hline $\begin{array}{l}\text { 1977-1985 Chang } \\
\text { con Campbell, } \\
\text { Cousineau, Ilan, } \\
\text { Grunwald, Wahl, Yu } \\
\text { etc. }\end{array}$ & $\begin{array}{l}\text { Células artificiales con sistema de multienzimas con co-factor de } \\
\text { reciclamiento par reacciones enzimáticas de varias pasos. }\end{array}$ \\
\hline $\begin{array}{l}1978 \\
\text { Naito y Yokoyama }\end{array}$ & Desarrollo de perfluorodecalin como sustituto sanguíneo. \\
\hline $\begin{array}{l}1980 \text { Lim y Sun } \\
\text { (Science) }\end{array}$ & Alginato-polilicina-alginato encapsulado en una célula artificial. \\
\hline $\begin{array}{l}1980 \text { Rosenthal y } \\
\text { Chang }\end{array}$ & $\begin{array}{l}\text { Célula artificial con membrana de complejo lípido-polímero con } \\
\mathrm{Na}^{+}, \mathrm{K}^{+} \text {, ATPasa. }\end{array}$ \\
\hline $\begin{array}{l}1980 \text { Djordjevich y } \\
\text { Miller }\end{array}$ & Membrana lipídica encapsulando $\mathrm{Hb}$. \\
\hline $\begin{array}{l}1985 \text { Mitsuno, } \\
\text { Ohyanagi }\end{array}$ & $\begin{array}{l}\text { Tratamiento clínico de perfluorodecalin como sustituto } \\
\text { sanguíneo. }\end{array}$ \\
\hline
\end{tabular}


TABLA 7. Conceptos y aplicaciones de las células artificiales poliméricas.

\begin{tabular}{|c|c|}
\hline AÑo & DESARROLLO \\
\hline 1986 Yuan y Chang & Célula artificial con microsomas y cytosol. \\
\hline $\begin{array}{l}1986 \text { Bourget y } \\
\text { Chang }\end{array}$ & $\begin{array}{l}\text { Presentación oral de célula artificial con enzimas para } \\
\text { modificación del metabolismo (feniquetonuria en rata). }\end{array}$ \\
\hline $\begin{array}{l}1986 \text { Sipehia, } \\
\text { Bannard y Chang }\end{array}$ & $\begin{array}{l}\text { Célula artificial con membrana que excluye a pequeñas } \\
\text { moléculas hidrofílicas pero permea a moléculas grandes } \\
\text { lipofílicas. }\end{array}$ \\
\hline $\begin{array}{l}1989 \text { Chang, Bourget } \\
\text { y Lister }\end{array}$ & $\begin{array}{l}\text { Célula artificial para la remoción selectiva de aminoácidos no } \\
\text { deseados en el organismo. }\end{array}$ \\
\hline $\begin{array}{l}1988 \text { Grupo Tsuchida } \\
2002 \text { Tsuchida et al. }\end{array}$ & $\begin{array}{l}\text { Desarrollo y prueba in vivo de un complejo sintético -hem en } \\
\text { liposoma y albúmina recombinante como sustituto sanguíneo. }\end{array}$ \\
\hline $\begin{array}{l}\text { 1989a Chang } \\
1989 \text { Palmour et al., } \\
\text { Chang }\end{array}$ & $\begin{array}{l}\text { Uso clínico de una forma farmacéutica oral de célula artificial } \\
\text { con enzima en pacientes con la enfermedad Lesch-Nyhan. }\end{array}$ \\
\hline 1988 Moss et al. & Tratamiento clínico con glutaraldehído entrecruzado Poly Hb. \\
\hline 1990 Hoffman & Hemoglobina humana recombinada. \\
\hline 1994 Yu y Chang & $\begin{array}{l}\text { Membrana nanoartificial polimérica biodegradable de glóbulo } \\
\text { rojo. }\end{array}$ \\
\hline $\begin{array}{l}1994 \text { Soon-Shiong } \\
\text { et al. }\end{array}$ & $\begin{array}{l}\text { Trasplante de islotes encapsulados en una célula artificial } \\
\text { en pacientes con diabetes tipo 1. Reportado como insulino } \\
\text { dependiente. }\end{array}$ \\
\hline $\begin{array}{l}1996 \text { Prakash y } \\
\text { Chang (Nature Med.) }\end{array}$ & $\begin{array}{l}\text { Célula artificial oral con células genéticamente modificadas en } \\
\text { modelo de rata urémica. }\end{array}$ \\
\hline $\begin{array}{l}1996 \text { Aebischer, } \\
\text { Lysagth et al. } \\
\text { (Nature Med) }\end{array}$ & $\begin{array}{l}\text { Fibra de polímero poroso para la encapsulación de células } \\
\text { modificadas genéticamente para pacientes con esclerosis. }\end{array}$ \\
\hline $\begin{array}{l}1998 \text { D'Agnillo y } \\
\text { Chang } \\
\text { (Nature Biotech) }\end{array}$ & $\begin{array}{l}\text { Nanobiotecnología para hemoglobina entrecruzada, catalasa } \\
\text { y superóxido dismutasa para la formación de PolyHb-CAT-SOD } \\
\text { soluble. }\end{array}$ \\
\hline 1998 Tsuchida & Vesícula lípidicas con Hb desarrollo y prueba en animales. \\
\hline 1999 Philips et al. & $\begin{array}{l}\text { Membrana lípidicas-PEG con Hb, incremento del tiempo de } \\
\text { recirculación. }\end{array}$ \\
\hline 2000 Liu y Chang & Co-encapsulación de hepatocitos y células madre adulta. \\
\hline $\begin{array}{l}2001 \text { Lörh et al. } \\
\text { (Lancet) }\end{array}$ & $\begin{array}{l}\text { Pruebas clínicas con células artificiales con mediadores celulares } \\
\text { para el tratamiento de carcinoma pancreático inoperable. }\end{array}$ \\
\hline 2002 Gould et al. & $\begin{array}{l}\text { Capacidad del soporte de vida de la polihemoglobina humana } \\
\text { en cirugía. }\end{array}$ \\
\hline 2002 Sprung et al. & $\begin{array}{l}\text { El uso de polihemoglobina bovina en pacientes quirúrgicos: } \\
\text { resultados de un ensayo multicéntrico ciego y aleatorio. }\end{array}$ \\
\hline $\begin{array}{l}2003 \text { Chang, } \\
\text { Powanda, Yu }\end{array}$ & $\begin{array}{l}\text { Membrana PEG-PLA con hemoglobina y enzimas de glóbulo rojo } \\
\text { en nanodimensiones. }\end{array}$ \\
\hline
\end{tabular}


TABLA 7. Conceptos y aplicaciones de las células artificiales poliméricas.

\begin{tabular}{|c|c|}
\hline AÑo & DESARROLLO \\
\hline $\begin{array}{l}2004 \text { Bloch et al., } \\
\text { Aebischer }\end{array}$ & $\begin{array}{l}\text { Estudio clínico fase } 1 \text { para terapia de la enfermedad de } \\
\text { Huntington empleando células modificadas genéticamente para } \\
\text { la secreción del factor neurotrófico. }\end{array}$ \\
\hline $\begin{array}{l}2004 \text { Yu y Chang } \\
\text { (Melanoma Res J.) }\end{array}$ & $\begin{array}{l}\text { Nanobiotecnológica de PolyHb-tyrosinasa en el crecimiento del } \\
\text { melanoma en un modelo de rata. }\end{array}$ \\
\hline $\begin{array}{l}2006 \text { Liu y Chang } \\
\text { (J. Liver Trans) }\end{array}$ & $\begin{array}{l}\text { Célula artificial con encapsulación células regeneradoras } \\
\text { del hígado en ratas con el } 90 \% \text { del hígado extirpado } \\
\text { quirúrgicamente. }\end{array}$ \\
\hline 2007 Yu y Roberts & $\begin{array}{l}\text { Empleo de células artificiales para la selección de restricción de } \\
\text { endonucleasas. }\end{array}$ \\
\hline 2007 Abe, H. et al. & $\begin{array}{l}\text { Efecto de vesículas de hemoglobina en reacción anafiláctica en } \\
\text { un modelo de rata. }\end{array}$ \\
\hline 2007 Sakai, H. et al. & $\begin{array}{l}\text { Reporte de la observación por un año de ratas Wistar después } \\
\text { de una infusión intravenosa de vesículas de hemoglobina. }\end{array}$ \\
\hline 2007 Tsai y Wong & $\begin{array}{l}\text { Patente } 7,307,150,2007 \text { conjugado de hemoglobina-dextran } \\
\text { como sustituto sanguíneo. }\end{array}$ \\
\hline $\begin{array}{l}2007 \text { Discher, D. } \\
\text { et al. }\end{array}$ & $\begin{array}{l}\text { Aplicación emergente de polimerosomas en el tratamiento de } \\
\text { un tumor. }\end{array}$ \\
\hline $\begin{array}{l}2008 \text { Chiellini, F. } \\
\text { et al. }\end{array}$ & $\begin{array}{l}\text { Polímeros micro/nanoestructurados para aplicación biomédica } \\
\text { y farmacéutica. }\end{array}$ \\
\hline 2009 Katz, JS. et al. & $\begin{array}{l}\text { Estabilización de la membrana en polimerosomas } \\
\text { biodegradables con poli(caprolactona-b-etilenglicol). }\end{array}$ \\
\hline 2010 Katz, JS. et al. & $\begin{array}{l}\text { Nueva ruta de síntesis para el copolímero (PCL-b-PEG) } \\
\text { para el desarrollo de una membrana funcionalizada en un } \\
\text { polimerosoma biodegradable. }\end{array}$ \\
\hline $\begin{array}{l}2010 \text { Rameez, S. } \\
\text { et al. }\end{array}$ & $\begin{array}{l}\text { Elaboración de polimerosomas con hemoglobina por el método } \\
\text { de extrusión a gran escala. }\end{array}$ \\
\hline 2010 Cho, HK. et al. & $\begin{array}{l}\text { Nanopartículas poliméricas, micelas y polimerosomas de } \\
\text { bloques de copolímero anfifílicas. }\end{array}$ \\
\hline 2010 Sakai, H. et al. & Vesículas de hemoglobina que imita a los glóbulos rojos. \\
\hline $\begin{array}{l}2011 \text { Mai'l'té, S. } \\
\text { et al. }\end{array}$ & $\begin{array}{l}\text { Coloide de gelatina con } \mathrm{Hb} \text { empleado como fluido preoperatorio } \\
\text { para el acarreo de oxígeno. }\end{array}$ \\
\hline 2011 Tanner, P. et al. & $\begin{array}{l}\text { Polimerosomas que imitan a las células biológicas que } \\
\text { pueden emplearse en la liberación controlada de fármacos y } \\
\text { biofármacos. }\end{array}$ \\
\hline 2011 Kim, SH. et al. & $\begin{array}{l}\text { Polimerosomas múltiples para la liberación programada de } \\
\text { múltiples componentes. }\end{array}$ \\
\hline $\begin{array}{l}2011 \text { Kamat, NP. } \\
\text { et al. }\end{array}$ & Ingeniería de polimerosomas para el desarrollo de protocélulas. \\
\hline
\end{tabular}


TABLA 7. Conceptos y aplicaciones de las células artificiales poliméricas.

\begin{tabular}{|l|l|}
\hline AÑo & DESARROLLo \\
\hline 2011 Perro, A. et al. & $\begin{array}{l}\text { Generación de polimerosomas complejos por el método de } \\
\text { doble emulsión con el empleo de microfluidos. }\end{array}$ \\
\hline 2011 Meng, F. et al. & $\begin{array}{l}\text { Polimerosomas de la nano a la microescala para el control } \\
\text { de la liberación de fármacos y vesículas robustas para virus e } \\
\text { imitación de células. }\end{array}$ \\
\hline 2012 Li, S. et al. & $\begin{array}{l}\text { Polimerosomas con membranas ionizables para liberación rápida } \\
\text { de proteínas intracelular. }\end{array}$ \\
\hline 2012 Liu, GY. et al. & $\begin{array}{l}\text { Polimerosomas como acarreadores de moléculas zwitterionic } \\
\text { (PC@QDs). }\end{array}$ \\
\hline 2012 Maíl'té, S. et al. & $\begin{array}{l}\text { Polimerosomas "gelly" en su interior con imitación de orgánulos } \\
\text { y citoplasma. }\end{array}$ \\
\hline 2012 Sakai, H. et al. & HBOC con hemoglobina de cerdo. \\
\hline 2012 Taguchi, K. et al. & $\begin{array}{l}\text { Evaluación farmacocinética después de una infusión de vesículas } \\
\text { de hemoglobina en monos cynomolgus durante } 40 \text { días. }\end{array}$ \\
\hline $\begin{array}{l}2012 \text { Li, D. et al. } \\
\text { et al. }\end{array}$ & Esferas de hemoglobina como portadores de oxígeno. \\
\hline $\begin{array}{l}2012 \text { Rameez, S. } \\
\text { et al. }\end{array}$ & $\begin{array}{l}\text { Liposoma encapsulando hemoglobina/nanopartículas de sílice } \\
\text { como acarreador de oxígeno. } \\
\text { superficie conjugada con poli (etilenglicol) para regular la } \\
\text { vasodilatación ocasionada por el óxido nítrico. }\end{array}$ \\
\hline $\begin{array}{l}\text { Copolímero: eficientes acarreadores de nanopartículas para la } \\
\text { terapia génica y vectorización de fármacos. }\end{array}$ \\
\hline
\end{tabular}

\section{Bibliografia}

Aebischer, P. (1996) Intrathecal delivery of CNTF using encapsulated genetically modified xenogenetic cells in amyotrophic lateral sclerosis patients. Nature Medical, 2: 696-699.

Afsaneh, L., Samuel, J. y Kwon, G.S. (2002) Poly(ethylene oxide)-block-poly(L-amino acid). Micelles for Drug Delivery. Advanced Drug Delivery Reviews, 54: 169-190.

Alayash, A. I. (2004) Oxygen therapeutics: Can we tame haemoglobin? Nature, 3: 152-159.

Anseth, K.S., Scott, R.A. y Peppas, N.A. (1996) Effects of ionization on the reaction behavior and kinetics of acrylic acid polymerization. Macromolecules, 29: 83088312.

Arifin, D.R. y Palmer, A.F. (2003) Determination of size distribution and encapsulation efficiencies of liposomes encapsulated hemoglobin by asymmetric flow fieldflow fractionation and multi-angle light scattering. Biotechnology Progress, 19: 1798-1811. 
Arifin, D.R. (2005) Cellular hemoglobin-based oxygen carriers as potential artificial blood substitutes. Ph. D. Thesis. University of Notre Dame. Indiana, USA. Mayo 2005. 159 p.

Bangham, A.D., Standish, M.M. y Watkins, J.C. (1965) Diffusion of univalent ions across the lamellae of swollen phospholipids. Journal Molecular Biology, 13: 238-252.

Bermudez, H., Brannan, A.K., Hammer, D., Bates, F.S. y Discher, D. (2002) Molecular weight dependence of polymersome membrane structure, elasticity and stability. Macromolecules, 35: 8203-8208

Bloch, J., Bachoud-Lévi, A.C., Déglon, N., Lefaucheur, J.P., Winkel, L.S, Palfi, J.P. Nguyen, C. Bourdet, P., Remy, P., Brugières, M., Boisse, F., Baudic, S.,Cesaro, P., Hantraye, P, .Aebischer, P. y Peschanski, M. (2004) Neuroprotective gene therapy for Huntington's disease, using polymer-encapsulated cells engineered to secrete human ciliary neurotrophic factor: Results of a phase I study. Human Gene Therapy, 15: 968-975.

Bonhard, K., (1976) Hemoglobin preparations for perfusion and infusion problems of large-scale production. Biomaterials Artificial Cells Artificial Organs, 16: 85-92.

Bourget, L. y Chang, T.M.S. (1986) Phenylalanine ammonia-lyase immobilized in microcapsules for the depleture of phenylalanine in plasma in phenylketonuric rat model. Biochimica et Biophysica Acta, 883: 432-438.

Brig, YKG., Maj P.D., Chatterjee, Lt. Col.T., Dhot, Col PS, Brig R.S. (2003) Artificial Blood. Malawi Journal of Aquaculture and Fisheries, 59, 1: 49-50.

Bunn, H.F. y Jandl, J.H. (1968) The renal handling of hemoglobin. Transaction American Society for Artificial Internal Organs, 81: 147.

Casas-Martínez, M. (2010) Análisis bioético del embarazo en testigos de Jehová y el rechazo transfusional. Cuadernos de Bioética, XXI: 327-329.

Chang T.M.S. (1999) Future prospects for artificial blood. Trends in Biotechnology, 17: 61-67

Chang, T.M.S. (2005). Therapeutic applications of polymeric artificial cells. Nature Rewiews/Drug Discovery, March, 4: 221-235.

Chang T.M.S. (2006) Blood substitutes base on Nanobiotechnology. Trends in Biotechnology, 24: 72-377.

Chang T.M.S. (2009) Nanobiotechnology for Hemoglobin Based Blood Substitutes. Critical Care Clinics, 25: 373-382

Chang T.M.S. (2004) A new red blood cell substitute. Critical Care Medical, 32: 612-613.

Chang T.M.S. (2006) Evolution of artificial cells using Nanobiotechnology of hemoglobin based RBC blood substitutes as an example. Artificial Cells, Blood Substitutes, and Biotechnology, 34: 551-566.

Chang, T.M.S. (1957) Hemoglobin corpuscles. Report of a research project for Honours Physiology. Medical Library, McGill University. Also reprinted as part of "30 anniversary in Artificial Red Blood Cells Research" J. Biomaterials, Artificial Cells y Artificial Organs 16: 1-9, 1988. And also in Chang's 2007 Monograph on 'Artificial Cells. Disponible en: <http://www.medicine.mcgill. ca/artcell/514.pdf>. 
Chang, T.M.S. (1971a) The in vivo effects of semipermeable microcapsules containing L-asparaginase on 6C3HED lymphosarcoma. Nature, 229: 117-118.

Chang, T.M.S. (1971b) Stabilisation of enzymes by microencapsulation with concentrated protein solution or by microencapsulation followed by cross-linking with glutaraldehydo. Biochemical and Biophysical Research Communications, 44: 1531-1536.

Chang, T.M.S. (1972a). Artificial Cells. American Lecture Series. Charles C. Thomas Publisher, Springfield, USA: 3-218. Disponible en línea en la web: <http:// www.artcell.mcgill.ca>. (Octubre 16, 2013.)

Chang, T.M.S. (1972b) Haemoperfusion over microencapsulated adsorbent in a patient with hepatic coma. Lancet, 2: 1371-1372.

Chang, T.M.S. (1975h) The one shot vaccine in socioeconomic and ethical implications of enzyme engineering. En Heden, C.G. (ed.), International Federation of Institutes for Advanced studies: 17-28. Stockolmo, Sweden.

Chang, T.M.S. (1976) Biodegradable semipermeable microcapsules containing enzymes, hormones, vaccines, and other biological. Journal Bioengineering, 1: 25-32.

Chang, T.M.S. (2007) Artificial cells. Biothechnology, nanomedicine, regenerative medicine, blood substitutes, bioencapsulation, cell/stem cell/therapy. Regenerative Medicine, Artificial Cells and Nanomedicine, vol. 1: 8-11. World Scientific Publishing Co. Pte. Ltd., Singapore.

Chang, T.M.S. (1964) Semipermeable microcapsules. Science, 146: 524-525.

Chang, T.M.S. (1965) Semipermeable aqueous microcapsules. Ph.D. Thesis. McGill University, Montreal.

Chang, T.M.S. (1966) Semipermeable aqueous microcapsules (“artificial cells”): with emphasis on experiments and extracorporeal shunt system. Artificial Internal Organs, 12: 13-19.

Chang, T.M.S. (1970) Nonthrombogenic microcapsules. US Patent, 3: 522, 346.

Chang, T.M.S. y Malave, N. (1970) The development and first clinical use of semipermeable microcapsules (artificial cells) as a compact artificial kidney. Artificial Internal Organs, 16: 141-148.

Chang, T.M.S. y Poznansky, M.J. (1968b) Semipermeable microcapsules containing catalase for enzyme replacement in acatalsaemic. Nature, 218: 242-245.

Chang, T.M.S. Macintosh, F.C. y Mason, S.G. (1966) Semipermeable aqueous microcapsules: I. Preparation and properties. Canadian Journal of Physiology and Pharmacology, 44: 115-128.

Chang, T.M.S., Powanda, D. y Yu, W.P. (2003) Ultrathin polyethylene-glycol-polylactide copolymer membrane nanocápsulas containing polymerized $\mathrm{Hb}$ and enzymes as nano-dimension red blood cell substitutes. Artificial Cells Blood Substitutes Immobilization Biotechnology, 3: 231-248.

Chang, T.M.S., Yu, Y.T. y Grunwald, J. (1982d) Artificial cells, inmobilized multienzyme systems and cofactors. Enzyme Engineering, 6: 451-561.

Chang, T.S.M. (1969a) Removal of endogenus and exogenous toxins by microencapsulated absorbent. Canadian Journal of Physiology and Pharmacology, 47: 163-168.

Chang, T.S.M. (1969d) Lipid-coated spherical ultrathinmembranes of polymer or 
cross-linked protein as possible cell membrane models. Federation Proceedings, 28: 461.

Chang, T.S.M. (1989a) Preparation and characterization of xanthine oxidase immobilized by microencapsulation in artificial cells for th removal of hypoxanthine. Biomaterials Artificial Cells and Artificial Organs, 17: 611-616.

Chang, T.M.S. (1989b) The use of modified hemoglobin as an oxygen carrying blood substitute. Transfusion Medical Review, 3: 213-218.

Chang, T.M.S., Johson, L.J. y Ransome, O.J. (1967) Semipermeable aqueous microcapsules: IV Nonthrombogenic microcapsules with heparine-complexed membranes. Canadian Journal of Physiology and Pharmacology, 45: 705-715.

Cho, H.K., Cheong, I.W., Lee, J.M., Kim, J.H. (2010) Polymeris nanoparticles, micelles and polymersomes from amphiphillic block copolymer. Korean Journal of Chemical Engineering, 27: 731-740.

Cheng, D.C., Mazer, D.C., Martineau, R (2004) A phase II dose-response study of hemoglobin raffimer (Hemolink) in elective coronary artery bypass surgery. The Journal of Thoracic and Cardiovascular Surgery, 127: 79-86.

Clark, L.C. Jr. y Gollan, F. (1966) Survival of mammals breathing organic liquids equilibrate with oxygen at atmospheric pressure. Science, 152: 1755.

D’Agnillo, F. y Chang, T.M.S. (1998a) Polyhemoglobin-superoxide dismutase-catalase as a blood substitute with antioxidant properties. Nature Biotechnology, 16: 667-671.

Dieryck, W., Pagnier, J., Poyart, C., Marden, M.C., Gruber, V., Bournat, P., Baudino, S. y Merot, B. (1999) Human haemoblobin from transgenic tobacco. Nature, 386: 29-30.

Discher D.E. y Ahmed F. (2006) Polymersomes. Annual Review of Biomedical Engineering, 8: 323-41.

Discher, D., Bermudez, H., Lee, J., Discher, B., Hammer, D. y Bates, F. (2001) Polymersomes: Thermomecanical properties through in vivo testing. Bioengineering Conference, ASME-Publications-Bed, 50: 543-544. American Society of Mechanical Engineers.

Djordjevich, L. y Miller, I.F. (1980) Synthetic erythrocytes from lipid encapsulated hemoglobin. Experimental Hematology, 8: 584.

Duan, L., Yan, X., Wang., A., Jia, Y. y Li, J. (2012) Highly loaded hemoglobin spheres as promising artificial oxygen carriers. ACS Nano, 6: 6897-6904.

Eastman, A. y Minei, J.P. (2009) Comparison of Hemoglobin-based Oxygen Carriers to Stored Human Red Blood Cells. Critical Care Clinics, 25: 303-310.

Förster, S. y Borchert, K. (2005) Encyclopedia of Polymer Science and Technology. John Wiley y Sons. USA, pp. 1-52.

Gaucher, C., Boura, C., Stoltz, J-F., Menu, P. (2006) Oxigen Therapeutics: Current Issues and New Challenges. Actas Bioquímicas, 7: 67-71.

Geyer, R.P., Monroe, R.G. y Taylor, K. (1968) Survival of rats totally perfused with a fluorocarbon-detergent preparation. En: Norman, J.C., Folkman, J., Hardison, W.G. et al. (eds.), Organ perfusion and preservation, Nueva York: Appleton Century Crofts: 85-96. 
Goliath (2005) Polymersomes Useful for Drug Delivery, Storage. Membrane and Separation Technology News. <http://goliath.ecnext.com/coms2/gi_0199-3618437/ Polymersomes-Useful-for-Drug-Delivery.htlm>.

Gong-Yan, L., Xiang-Sheng, L., Shan-Shan, W., Chao-Jian, Ch., Jian, J. (2012) Biomimetic polymersomes as carriers for hydrophilic quantum dots. Langmuir, 28: 557-562.

Gould, S.A., Moore, E.E., Hoyt, D.B., Ness, P.M-, Norris, E.J., Carson, J.L., Hides, G.A., Freeman, I.H.G., DeWoskin, R. y Moss, G.S. (2002) The life-sustaining capacity of human polymerized hemoglobin when red cells might be unavailable. Journal of American College of Surgeon, 195: 445-452.

Gregoriadis, G. (ed.) (1979) Drug Carriers in Biology and Medicine. Nueva York: Academic Press, Inc.

Hae, W. K. y Greenburg, A.G. (2006) Toward $21^{\text {st }}$ century blood component replacement therapeutics: Artificial oxygen carriers, platelet substitutes, recombinant clotting factors, and others. Artificial Cells, Blood Substitutes, and Biotechnology, 34: 537-550.

Hamidi, M., Shahbazi, M., Rostamizadeh, K. (2012) Copolymers: Efficient carriers for intelligent nanoparticule drug targeting and gene therapy. Macromolecular Bioscience, vol. 12 (2): 144-164.

Hamley, I.W. (2003) Nanostructure fabrication using block copolymer. Nanotechnology, 14: R39-R54.

Hayward, R.C., Utada, A.S., Dan, N. y Weitz D.A. (2006) Dewetting instability during the formation of polymersomes from block-copolymer-stabilized double emulsions. Langmuir, vol. 22 (10): 4457-4461.

Heddle, N.M., Cook, R.J., Arnold, D.M., Crowther, M.A., Warkentin, T.E., Weber, K.E., Hirsh, J., Barty, R.L., Liu, Y., Lester, C., Eikelboom, J.W. (2012). The effect of blood storage duration on in-hospital mortality: a randomized controlled pilot feasibility trial. Transfusion, vol. 52 (6): 1203-1212.

Hoffman, S.J., Looker, D.L., Roehrich, J.M., (1990) Expression of fully functional tetrameric human hemoglobin in Escherichia coli. Proceedings National Academic Science USA, 87: 8521-8525.

Kamat, N.P., Katz, J.S., Hammer, D.A. (2011) Engineering polymersomes protocells. The Journal of Physical Chemistry Letters, 2: 1612-1623.

Kamat, N.P., Robbins, G.P., Rawson, J., Therien, M.J., Dmoschowski, I. J. y Hammer, D. A. (2010) A generalized system for photoresponsive membrane rupture in polymersomes. Advanced Functional Materials, 20: 2588-2596.

Kaneda, S., Ishizuka, T., Goto, H., Kimura, T., Inaba, K., Kasukawa, H. (2009) Liposome-Encapsulated Hemoglobin, TRM-645: Current Status of the Development and Important Issues for Clinical Application. Artificial Organs, 33: 146-152.

Katz, J.S., Levine, D.H., Davis, K.,P., Bates, F.S., Hammer, D.A., Burdick, J.A. (2009) Membrane stabilization of biodegradable polymersomes. Langmuir, 25: 44294434.

Katz, J.S., Zhong, S., Ricart, B.G., Pochan, D.J., Hammer, D.A., Burdick, J.A. (2010) Journal of the American Chemical Society, 132: 3654-3655. 
Kjellstrom, B. T. (2003) Blood Subtitutes: Where do we stand today? Journal of Internal Medicine, 253: 495-497.

Klein, H. G. (2002) Blood Substitutes: How Close to a Solution? Oncology, 16: 147-151. Li, S., Meng, F., Wang, Z., Zhong, Y., Zheng, M., Liu, H., Zhong, Z. (2012) Biodegradable polymersomes with an ionizable membrane: Facile preparation, superior protein loading and endosomal $\mathrm{pH}$-responsive protein release. European Journal of Pharmaceutics and Biopharmaceutics, 82: 103-111.

Lim, F. y Sun, A.M. (1980) Microencapsulated islets as bioartificial endocrine pancreas. Science, 210: 908-909.

Liu, Z.C. y Chang, T.M.S. (2000) Effects of bone marrow cells on hepatocytes: When cocultured or co-encapsulated together. Artificial Cells, Blood Substitutes, and Immobilization Biotechnology, 28: 365-374.

Liu, Z.C., y Chang, T.M.S. (2006a) Transdifferentiation of bioencapsulated bone marrow cells into hepatocyte-like cells in the $90 \%$ hepatectomized rat model. Journal Liver Transplantation, 12: 566-572.

Lorenceau, E., Utada, A.S., Link, D.R., Cristóbal, G., Joanicot, M. y Weitz, D.A. (2005) Generation of Polymersomes from Double-Emulsions. Langmuir, 21: 91183-9186.

Lörh, M., Hoffmeyer, A., Kröger, J.C. (2001) Microencapsulated cell-mediated treatment of inoperable pancreatic carcinoma. Lancet, 357: 1591-1592.

Lowe, K. C. (2002) Perfluorochemical respiratory gas carriers: Benefits to cell culture systems. Journal of Fluorine Chemistry, 118: 19-22.

Lowe, K. C. (2006) Blood substitutes: From chemistry to clinic. Journal of Material Chemistry, 16: 4189-4196.

Lowe, K. C. y Ferguson, E. Benefit, A. y Risks, C. (2003) Perceptions in transfusion medicine: Blood and blood substitutes. Journal of Internal Medicine, 253: 498-507.

Mail'té, M., Sandre, O., Lecommandoux, S. (2012) Polymersomes in "gelly" polymersomes: Toward structural cell mimicry. Langmuir, 28: 2035-2043.

Mathivet, L., Cribier, S. y Devaux, P.F. (1996) Shape change and physical properties of giant phospholipid vesicles prepared in the presence of an AC electric field. Biophysical Journal, 70: 1112-1121.

Meng F., Engbers G.H.M. y Feijen J. (2005) Biodegradable polymersomes as a basis for artificial cells: Encapsulation, release and targeting. Journal of Controlled Release, 101: 187-198.

Meng, F. y Zhong, Z. (2011) Polymersomes spanning from nano to microscale: Advanced vehicles for controlled drug delivery and robust vesicle for virus and cell mimicking. The Journal of Physical Chemistry Letters, 2: 1533-1539.

Meng, F., Hiemstra, C., Engbers, G. y Feijen, J. (2003) Biodegradable Polymersomes. Macromolecules, 36: 3004-3006.

Meng, F.M. y Angelova, M.I. (1998) Giant vesicles: Imitating the cytological processes of cell membranes. Access Chemical Resume, 31: 189-797.

Ming, T.S.C. (2004) Artificial cell bioencapsulation in macro, micro, nano, and molecular dimensions: Keynote lecture. Artificial, Cells, Blood Substitutes and Biotechnology. 32: 1-23. 
Mingxian, L., Lihuan, G., Liuhua, Ch., Dazhang, Z., Zijie, X., Zhixian, H., Longwu, Ch. (2012) A novel liposome-encapsulated hemoglobin/silica nanoparticles as an oxygen carrier. International Journal of Pharmaceutics, 427: 354-357.

Mitsuno, T. y Ohyanagi, I. (1985) Present status of clinical studies of fluosol-DA (20\%) in Japan. En: Tremper, K.K. (ed.), Perfluorochemical oxygen transport. Boston: Little Brown \& Co., 169-184.

Moss, G.S., Gould, S.A., Sehgal, L.R. (1988) Hemoglobin solution-from tetramer to polymer. Biomaterials Artificial Cells Artificial Organs, 16: 57-69.

Naito, R. y Yokoyama, K. (1978) An improved perfluorodecalin emulsion. En: Jamieson, G.A. y Greenwalt, T.J. (eds.). Blood substitutes and plasma expanders. Nueva York: Alan R. Liss Inc.: 81.

Napolitano L.M. (2009) Hemoglobin-based oxygen carriers: First, second or third generation? Human or bovine? Where are we now? Critical Care Clinics, 25: 279-301.

Ness, P.M., Cushing M.M. (2007) Oxygen therapeutics. Archives of Phatology \& Laboratory Medicine, 131: 734-41.

Palacios, A.J., Flores, R.H. y Guillot, J. (1982) Caracterización de copolímeros. Revista Sociedad Química de México, 26: 15-25.

Palmour, R.M., Goodyer, P., Reade, T. y Chang, T.M.S. (1989) Microencapsulated xanthine oxidase as experimental therapy in Lesch-Nyhan disease. Lancet, 2: 687-688.

Pata, V. y Dan, N. (2003) The effect of chain length on protein solubilization in polymer- based vesicles (polymersomes). Biophysical Journal, 85: 2111-2118.

Philips, W.T., Klipper R.W., Awasthi V.D., Rudolph A.S., Cliff R., Kwasiborski V., Goins B.A. (1999) Polyethylene glycol-modified liposome-encapsulated hemoglobin: A long circulating red cells substitutes. Journal Pharmaceutical Experimental Therapeutic, 288: 665-670.

Phillips, W. T., Klipper, R. W., Vibhudutta, A. D., Rudolph, A. S., Cliff, R., Kwasiborski, V. y Goins, B. A. (1999) Polyethylene glycol-modified liposome-encapsulated hemoglobin: A long circulating red cell substitute. Journal of Pharmacology and Experimental Therapeutics, 288: 665-670.

Praskash, S. y Chang, T.M.S. (1996) Microencapsulated genetically engineered live E. coli DH5 cells administered orally to maintain normal plasma urea level in uremic rats. Nature Medical, 2: 883-887.

Radillo-González, A. (2004) Alternativas farmacológicas de la transfusión. Gaceta Médica, 140 (3): S152-S156.

Rameez, S., Bamba, I., Palmer, A.F. (2010) Large scale production of vesicles by hollow fiber extrusion: A novel method for generating polymersomes encapsulated hemoglobin dispersion. Langmuir, 26: 5279-5285.

Rameez, S., Guzman, N., Banerjee, U., Fontes, J., Paulaitis, M.E., Palmer,M.E., Palmer, A.F., Patel, R.P. y Honavar, J. (2012) Encapsulation oh hemoglobin inside liposomes surface conjugated with poly(ethylene glycol) attenuates their reactions with gaseous ligands and regulates nitric oxide dependent vasodilation. Biotechnology Progress, 28: 636-645. 
Riess, J. G. (2001) Oxygen carriers ("blood substitutes”)-Raison d'etre, chemistry and some physiology. Chemical Reviews, 101: 2797-2919.

Ruth, D., Lorella, I. (2005) Role of delivery system in development of blood substitute. Advance Drug Delivery Reviews, 57: 2215-37.

Rodríguez, M.H. (2011) Enfermedades infecciosas por tranfusión en México. Revista Mexicana de Medicina Transfusional, 4: 78-90.

Rojo J. (2009) Tamizaje de la enfermedad de Chagas en bancos de sangre. Situación actual en México. Memorias del Centenario del descubrimiento de la Enfermedad de Chagas. Facultad de Medicina, UNAM, 41-43.

Rojo, J. (2010) El Centro Nacional de Transfusión Sanguínea. Revista de Medicina. Hospital General de México, 73: 209-210.

Rosenthal, A.M. y Chang, T.M.S. (1980) The incorporation of lipid and $\mathrm{Na}^{+}-, \mathrm{K}^{+}-$ ATPase into the membranes of semipermeable microcapsules. Journal of Membrane Science, 6: 329-338.

Sakai, H. (2012) Present situation of development of cellular-type hemoglobinbased oxygen carrier (hemoglobin-vesicles) Current Drug Discovery Technologies, 9: 188-193.

Sakai, H., Sou, K., Horinouchi, H., Kobayashi, K. y Tsuchida, E. (2010) Hemoglobinvesicle, a cellular artificial oxygen carrier that fulfills the physiological roles of the red blood cell structure. Oxygen Transport to Tissue XXXI. Advances in experimental Medicine and Biology, 662: 433-438.

Salazar, B.Y., Makena, C.H., Martini, J., Messmer, C., Frienesenecker, B., Cabrales, P., Tsai, A.G. e Intaglietta, M. (2011) Vasoactive hemoglobin improves survival in hemodilution followed be hemorrhagic shock. Critical Care Medicine, 39: 14611466.

Sánchez-Guerrero, S.A. (2010) La seguridad de la transfusión sanguínea en México. Revista Medicina Universitaria, 12: 79-83.

Schumacher Y. O. y Ashenden M. (2004) Doping with artificial oxygen carriers. Sports Medicine, 34: 141-150.

Serrano, J.J.M., Villareal, E.R., Galicia, L.R., Vargas, E.R.D., Martínez, L.G. y Mejía, A.F.D. (2009) Detección de anticuerpos circulantes en donantes de sangre en México. Revista Panamericana de Salud Pública/Pan. Am. J. Public Health, 26: 355-359.

Serrano, X.V. (2006) Hemotransfusión como factor de riesgo en cirugía cardiaca. Archivos de Cardiología de México, 76, Supl. 2/S2: 86-91.

Shander, A. y Goodnough, L.T. (2009) Why an alternative to blood transfusion? Critical Care Clinic, 25: 261-277.

Sharma A., Arora, S., Grewal, P., Dhillon, V., Kumar, V. (2011) Recent innovations in delivery of artificial blood substitute: A review. International Journal of Applied Pharmaceutica, 3: 1-5.

Shin-Hyun, K., Ho Cheung, S., Woong, J., Jun-Cheol, Ch., Weitz, D.A. (2011) Multiple polymersomes for programmed release of multiple components. Journal of American Chemical Society, 133: 15165-15171.

Sipheia, R., Bannard, R.A.B. y Chang, T.M.S. (1986a) Adsorption of large lipophilic 
molecules with exclusion of small hydrophilic molecules by microencapsulated activated charcoal formed by coating with polyethylene membrane. Journal of Membrane Science, 29: 277-286.

Smith, C., Lieberman, M. y Marks, A. (2013) Marks' basic medical biochemistry: A clinical approach. 4a. ed. China: Lippincott Williams y Wilkins. 969 p.

Soo, P.L. y Eisenberg, A. (2004) Preparation of block copolymer vesicles in solution. Journal of Polymer Science: Part B: Polymer Physics, 42: 923-938.

Soon-Shiong, P. (1994) Insulin independence in a type 1 diabetic patient after encapsulated islet transplantation. Lancet, 343: 950-951.

Sprung, J., Kindscher, J.D., Wahr, J.A. (2002) The use of bovine Hb glutamer-250 (Hemopure) in surgical patients: result of a multicenter, randomized, singleblinded trial. Anesthesia Analgesia, 94: 799-808.

Takeoka, S., Sakai, H., Kose, T., Mano, Y., Seino, Y., Nishide, H. y Tsuchida, E. (1997) Methemoglobin formation in hemoglobin vesicles and reduction by encapsulated thiols. Bioconjugate Chemistry. 8: 539-544.

Tam, S.C., Blumenstein, J. y Wong, J.T. (1976) Dextran hemoglobin. Proceedings National Academic Science USA, 73: 2128.

Tanner, P., Baumann, P., Enea, R., Onaca, O., Palivan, C., Meier, W. (2011) Polymeric vesicles: From drug carriers to nanoreactors and artificial organelles. Accounts of Chemical Research, 44: 1039-1049.

Tena, C.T. y Sánchez, J.M.G. (2005) La transfusión sanguínea y los derechos del paciente. Revista CONAMED, 10: 20-26.

Teramura, Y., Kanazawa, H., Sakai, H., Takeoka, S. y Tsuchida, E. (2003) Prolonged oxygen-carrying ability of hemoglobin vesicles by coencapsulation of catalase in vivo. Bioconjugate Chemistry, 14: 1171-1176.

Tsuchida, E. (ed.) (1998) Present and future perspectives. Blood Substitutes, vol. 1. Amsterdam: Elsiever: 267.

Tsuchida, E., Komatsu, T., Yanagimoto, T. y Sakai, H. (2002) Preservation stability and in vivo administration of albumin-heme hydrid solution as entirely synthetic oxygen-carrier. Polymer Advances Technology, 13: 845-850.

Tsuchida, E., Nishide, H. y Ohno, H. (1988) Liposome/heme as a totally synthetic oxygen carrier. Biomaterials Artificial Cells and Artificial Organs, 16: 313-319.

$\mathrm{Xu}$, J.P., Chen, V.W. y Shen, J.C. (2004) Novel biomimmetic polymersomes as polymer therapeutics of drug delivery. Journal Controlled Release, 107: 502-512.

Yu, B.L. y Chang, T.M.S. (2004a) In vitro and in vivo effects of polyhemoglobin tyrosinase on murine B16F10 melanoma. Melanoma Research Journal, 14: 197202.

Yu, W.P. y Chang, T.M.S. (1994) Submicron biodegradable polymer membrane hemoglobin nanocápsulas as potential blood substitutes: A preliminary report. Artificial Cells Blood Substitute Immobil Biotechnology, 22: 889-894.

Yuan, Z.Y. y Chang, T.M.S. (1986) Rat microsomes and cytosol immobilized by microencapsulation in artificial cells. International of Artificial Organs, 9: 63-68. 